\title{
Dietary patterns and nutritional adequacy in a Mediterranean country
}

\author{
Lluís Serra-Majem ${ }^{1,2 *}$, Maira Bes-Rastrollo ${ }^{3}$, Blanca Román-Viñas², Karina Pfrimer ${ }^{2,4}$, \\ Almudena Sánchez-Villegas ${ }^{1,3}$ and Miguel A. Martínez-González ${ }^{3}$ \\ ${ }^{1}$ Department of Clinical Sciences, University of Las Palmas de Gran Canaria, PO Box 550, 35080 Las Palmas de Gran Canaria, \\ Spain \\ ${ }^{2}$ Community Nutrition Research Centre of the Nutrition Research Foundation, University of Barcelona Science Park, Baldiri \\ Reixac 4, 08028 Barcelona, Spain \\ ${ }^{3}$ Department of Preventive Medicine and Public Health, University of Navarra, Irunlarrea 1, 31080 Pamplona, Spain \\ ${ }^{4}$ Division of General Internal and Geriatric Medicine, Department of Internal Medicine of Ribeirão Preto, University of São Paulo, \\ Avenida Bandeirantes 3900, 14049-900 Ribeirão Preto, SP, Brazil
}

(Received 10 April 2009 - Revised 12 June 2009 - Accepted 15 June 2009)

Dietary patterns have been related to health outcomes and morbi-mortality. Mediterranean diet indexes are correlated with adequate nutrient intake. The objective of the present study was to analyse the adequacy of nutrient intake of a posteriori defined Mediterranean (MDP) and Western (WDP) diet patterns in the Seguimiento Universidad de Navarra (SUN) cohort. A sample of 17197 subjects participated in the study. Participants completed a 136-item validated semi-quantitative FFQ. Principal component analysis was used to define dietary patterns. Individuals were classified according to quintiles of adherence based on dietary pattern scores. Non-dietary variables, such as smoking and physical activity habits, were also taken into account. The probability approach was used to assess nutrient intake adequacy of certain vitamins (vitamins $\mathrm{B}_{12}, \mathrm{~B}_{6}, \mathrm{~B}_{3}, \mathrm{~B}_{2}, \mathrm{~B}_{1}, \mathrm{~A}, \mathrm{C}, \mathrm{D}$ and $\mathrm{E}$ ) and minerals ( $\mathrm{Na}, \mathrm{Zn}$, iodine, Se, folic acid, $\mathrm{P}, \mathrm{Mg}, \mathrm{K}, \mathrm{Fe}$ and $\mathrm{Ca}$ ). Logistic regression analysis was used to assess the adequacy of nutrient intake according to adherence to dietary patterns. WDP and MDP were defined. A higher quintile of adherence to an MDP was associated to a lower prevalence of inadequacy for the intake of $\mathrm{Zn}$, iodine, vitamin $\mathrm{E}, \mathrm{Mg}, \mathrm{Fe}$, vitamin $\mathrm{B}_{1}$, vitamin $\mathrm{A}, \mathrm{Se}$, vitamin $\mathrm{C}$ and folic acid. The adjusted OR for not reaching at least six (or at least ten) nutrient recommendations were 0.09 (95\% CI: 0.07, 0.11) (and 0.02 (95\% CI: 0.00, 0.16)) for the upper quintile of MDP and $4.4(95 \%$ CI: $3 \cdot 6,5 \cdot 5)$ and $2.5(95 \%$ CI: $1 \cdot 1,5 \cdot 4)$ for the WDP. The MDP was associated to a better profile of nutrient intake.

Dietary patterns: Factor analysis: Probability approach: Nutrient adequacy: Mediterranean diet: Micronutrient intake

A priori or a posteriori defined dietary patterns have been developed to evaluate the interaction and functions that the combination of foods and nutrients may have on human health given that single nutrients or foods may not completely explain the ethiopatogenesis of nutrition-related diseases ${ }^{(1-5)}$. Several chronic diseases, such as cardiovascular diseases (CVD), diabetes mellitus and certain cancers (breast cancer, colon cancer and others), have been associated with the combined intake of certain nutrients. For instance, a high intake of red meat is not only associated to a high intake of Saturated fatty acids (SFA) and cholesterol, but also to a high ingestion of nitrites, or dietary glycoxidation products, the joint action of which can be involved in the aetiology and progression of diabetes $^{(6)}$. If these interactions are not taken into account when analysing the contribution of every nutrient to disease risk, incorrect conclusions about the role of fatty acids on health may be derived.

Some healthy patterns have been defined from the evaluation of dietary patterns in the population. The 'Prudent', the 'Healthy' or the 'Energy Density' patterns have a very similar food profile: a high intake of fruits, vegetables, fish, legumes, whole grain cereals ${ }^{(1,2,4)}$. The Mediterranean diet, a model of a healthy eating, has been quantified in several diet indexes aiming to sum up the foods and nutrients that contribute to the benefits that such a dietary pattern has on health ${ }^{(7)}$. Dietary patterns have been associated to certain health outcomes, including total mortality ${ }^{(1)}$. They can also be of use to evaluate adherence to dietary recommendations ${ }^{(8)}$. When the dietary pattern of a certain population complies with dietary recommendations, it is expected that a higher adherence to the pattern will help to meet adequate nutrient intakes. Certain dietary patterns defined as 'healthy' have been validated against nutrient intake adequacy ${ }^{(9)}$ showing that some of them correlate with the intake of specific vitamins and minerals. In the EURopean micronutrient RECommendations Aligned project (www.EURRECA.org), researchers have been working on the association of the science of estimating nutritional adequacy in Europe with the evaluation of dietary intake patterns within the context of nutritional epidemiology.

Abbreviations: MDP, Mediterranean dietary pattern; SUN, Seguimiento Universidad de Navarra; WDP, Western dietary pattern.

* Corresponding author: Lluís Serra-Majem, fax +3493 4034543, email lserra@dcc.ulpgc.es 
The purpose of the present study was to correlate an a posteriori defined Mediterranean diet pattern (MDP) against the assessment of nutrient intake adequacy in the 'Seguimiento Universidad de Navarra (SUN)' (Follow-up Study of the University of Navarra) cohort study.

\section{Subjects and methods}

The methods for the recruitment and collection of data from the participants of the prospective SUN cohort study have been described in detail in previous publications ${ }^{(10)}$. The SUN study was designed to determine associations between the diet and the occurrence of chronic conditions such as obesity through a self-administered questionnaire mailed every 2 years. The SUN participants are all university graduates from all Spanish provinces. The recruitment of this dynamic cohort began in December 1999, and as of the time the present analysis was performed (February 2008), it included 19057 subjects. After excluding subjects with extreme values for total energy intake $(<3347.2 \mathrm{~kJ} / \mathrm{d}$ $(800 \mathrm{kcal} / \mathrm{d})$ or $>16736 \mathrm{~kJ} / \mathrm{d}(4000 \mathrm{kcal} / \mathrm{d})$ for $m e n$, $<2092 \mathrm{~kJ} / \mathrm{d}(500 \mathrm{kcal} / \mathrm{d})$ or $>14644 \mathrm{~kJ} / \mathrm{d}(3500 \mathrm{kcal} / \mathrm{d})$ for women; $n$ 1301) or with missing values in the variables of interest ( $n$ 559), 17197 subjects remained.

The present study was approved by the Institutional Review Board of the University of Navarra. Informed consent was implied by the voluntary completion of the baseline questionnaire.

\section{Dietary assessment}

At baseline, participants completed a semi-quantitative Food Frequency Questionnaire (FFQ) that had been previously validated in Spanish subjects ${ }^{(11)}$. There were nine options for the average frequency of intake (ranging from never/almost never to at least six times per day) for 136 food items in the previous year, based on typical portion sizes. Nutrient intake was calculated using the most up-to-date food composition tables for Spain ${ }^{(12,13)}$. Micronutrients were adjusted for total energy intake through the residual method. The micronutrients examined were: $\mathrm{Na}$; $\mathrm{Zn}$; iodine; $\mathrm{Se}$; folic acid; $\mathrm{P} ; \mathrm{Mg} ; \mathrm{K}$; Fe; Ca; vitamins $\mathrm{B}_{12} ; \mathrm{B}_{6} ; \mathrm{B}_{3} ; \mathrm{B}_{2} ; \mathrm{B}_{1} ; \mathrm{A} ; \mathrm{C} ; \mathrm{D} ; \mathrm{E}$. Fibre was also examined.

Assessment of dietary pattern. We used baseline dietary intake data for principal component analysis to identify dietary pattern factors among the participants of the SUN cohort. The 136 food items included in the semi-quantitative FFQ were grouped into thirty pre-defined food categories, using as a unit of measurement grams per day. The approach used to determine the number of factors to be extracted was the Scree plot examination ${ }^{(14)}$. To achieve better interpretability, we used an orthogonal rotation procedure (varimax rotation) obtaining results in factors (i.e. dietary patterns) that were not correlated with each other. We determined the number of factors retained by the amount of variance explained by each pattern and the natural interpretation of each pattern generated. Food groups that loaded $>0.30$ were considered to be making a relevant contribution to the factor. The factor score for each pattern was constructed by summing observed consumption of the component food items weighted by their factor loadings. Thus, each individual received a factor score for each identified pattern. A higher score suggests better adherence to a certain dietary pattern ${ }^{(14)}$.

The factor analysis identified two major factors that were labelled as the Western dietary pattern (WDP; factor 1) and the Mediterranean Diet Pattern (MDP; factor 2).

Assessment of nutrient intake adequacy. The probability of intake adequacy for fifteen nutrients was calculated using the dietary reference intakes ${ }^{(15-20)}$. By using the probability approach $^{(21)}$, we calculated the probability of adequacy for $\mathrm{Zn}$, iodine, Se, folic acid, $\mathrm{P}, \mathrm{Mg}, \mathrm{Fe}$, vitamins $\mathrm{B}_{12}, \mathrm{~B}_{6}, \mathrm{~B}_{3}$, $\mathrm{B}_{2}, \mathrm{~B}_{1}, \mathrm{~A}, \mathrm{C}$ and $\mathrm{E}$, for each subject. To calculate the probability of adequacy for $\mathrm{Fe}$ intake, the distribution of $\mathrm{Fe}$ intake was log transformed.

Assessment of non-dietary variables. The baseline evaluation also included questions for the assessment of medical history, health habits, lifestyle and socio-demographic variables. There were forty-six non-dietary items for men and fifty-four for women. Participants were categorised as smokers, non-smokers or former smokers. The number of hours spent in sedentary activities such as daily hours of television viewing, daily hours driving, daily hours sitting and daily hours napping was quantified. Physical activity levels were also determined through a validated questionnaire that included information about seventeen activities such as walking, running, cycling, swimming, judo, soccer, skiing or sailing. The questionnaire had been validated by the SUN group using a triaxial accelerometer as the gold standard. Physical activity during leisure time (estimated as metabolic equivalent (MET)-h/week) derived from the questionnaire moderately correlated with $\mathrm{kcal} / \mathrm{d}$ assessed through the accelerometer (Spearman's $\rho=0.507,95 \%$ CI: 0.232, 0.707, $P<0.001)^{(22)}$. To quantify the volume of activity during leisure time, an activity MET index was computed by assigning a multiple of RMR (MET score) to each activity ${ }^{(23)}$, and the time spent in each of the activities was multiplied by the MET score specific to each activity, and then summed for overall activity, obtaining a value of overall weekly MET hours.

\section{Statistical analyses}

Dietary pattern scores were used to rank individuals according to their degree of conformity or adherence to a given dietary pattern. Scores for both patterns were divided into quintiles and participants were classified according to quintiles of adherence to a WDP (factor 1) and to a MDP (factor 2). Pearson's correlation coefficients were used to assess the relationship between dietary patterns and dietary and nondietary variables, as well as computed nutrient intake from the FFQ.

To assess the adjusted number of non-compliance with recommendations for each quintile of adherence to each dietary pattern, analyses of covariance were performed. Non-conditional logistic regression analyses were used to calculate the age and sex OR and $95 \% \mathrm{CI}$ of failing to comply with six or more recommendations (the median number of unmet recommendations was six). We repeated all the analyses using ten or more unmet recommendations (half the number of recommendations assessed) as the cutoff point. Tests of linear trend across increasing categories of adherence to dietary patterns were conducted by assigning 
medians of factor scores to each dietary pattern (MDP and WDP) and treating them as a continuous variable.

All $P$ values presented are two-tailed; $P<0.05$ was considered statistically significant.

\section{Results}

Details of the Pearson's correlation coefficient between food intake and the two factors defined, the WDP and MDP, are represented in Table 1. The Western pattern was correlated with the intake of red and processed meat, eggs, sauces, precooked food, fast food, energy soft drinks, sweets, whole dairy and potatoes and showed a negative correlation with the consumption of low-fat dairy. Those food groups identified in the 'Mediterranean' pattern (factor 2) included olive oil, poultry, fish, low-fat dairy, legumes, fruits and vegetables.

Table 2 shows the characteristics of the 17197 participants of the SUN cohort according to the quintiles of adherence to the two dietary patterns previously defined, the MDP and WDP. A higher adherence of women to the Mediterranean diet was observed. For the Western pattern, the tendency was the opposite (higher proportion of males following such pattern). A higher quintile of adherence to the MDP was associated to a lower prevalence of smokers and ex-smokers. The tendency was the opposite for the WDP. No differences were seen for the number of hours spent in sedentary activities. However, a higher quintile of adherence to an MDP was related to a higher level of physical activity during leisure time, expressed in MET-h/week.

A higher quintile of MDP adherence was associated to a lower percentage of energy coming from total fat and SFA intakes. No differences in the intake of MUFA across the quintiles were seen, though the ratio of MUFA to SFA monotonically increased with increased adherence to the $\operatorname{MDP}$ ( $P$ for trend $<0 \cdot 001)$. The percentage of energy coming from protein

Table 1. Pearson's correlation coefficients* for the relationship between baseline food consumption and factors representing dietary patterns $(n 17197)$

\begin{tabular}{lcc}
\hline & \multicolumn{2}{c}{ Dietary patterns } \\
\cline { 2 - 3 } & $\begin{array}{c}\text { Factor 1 } \\
\text { ('Western') }\end{array}$ & $\begin{array}{c}\text { Factor 2 } \\
\text { ('Mediterranean') }\end{array}$ \\
\hline Olive oil (g/d) & - & 0.32 \\
Poultry (g/d) & - & 0.38 \\
Red meat (g/d) & 0.54 & - \\
Processed meat (g/d) & 0.50 & - \\
Eggs $(\mathrm{g} / \mathrm{d})$ & 0.37 & - \\
Fish $(\mathrm{g} / \mathrm{d})$ & - & 0.59 \\
Sauces $(\mathrm{g} / \mathrm{d})$ & 0.42 & - \\
Pre-cooked food (g/d) & 0.41 & - \\
Fast food (g/d) & 0.57 & - \\
Energy soft drinks (g/d) & 0.35 & - \\
Commercial sweets $(\mathrm{g} / \mathrm{d})$ & 0.40 & - \\
Whole fat dairy (g/d) & 0.43 & - \\
Low-fat dairy (g/d) & -0.31 & 0.37 \\
Legumes (g/d) & - & 0.30 \\
Vegetables (g/d) & - & 0.68 \\
Fruits $(\mathrm{g} / \mathrm{d})$ & - & - \\
Potatoes $(\mathrm{g} / \mathrm{d})$ & 0.45 & \\
\hline
\end{tabular}

${ }^{*}$ Correlation coefficients $<0.3$ were omitted for simplicity. intake increased across the quintiles of adherence to an MDP, carbohydrate intake was low (43-44\%) and of similar value across all the quintiles. The analysis of fibre intake and also the intake of all the micronutrients under study (except $\mathrm{Na}$ ) showed increasing values with increasing quintiles of adherence to the MDP.

A higher adherence to the WDP was associated with a higher percentage of energy intake coming from fat, MUFA, PUFA and SFA and a lower percentage of energy from carbohydrate. The ratio of MUFA to SFA monotonically decreased with increased adherence to the WDP ( $P$ for trend $<0.001)$. The intake of fibre decreased across the quintiles of adherence to the WDP. Almost all the values for micronutrient intake decreased with the increasing quintiles of adherence to the WDP. Only the intake of $\mathrm{Na}$, vitamin $B_{12}$ and vitamin $B_{3}$ increased across the quintiles of the WDP.

Table 3 shows the percentage of participants who did not comply with nutrient intake recommendations according to the quintiles of adherence to MDP and WDP. The highest quintile of adherence to an MDP showed the lowest prevalence of non-compliance for intakes of $\mathrm{Zn}$, iodine, vitamin $\mathrm{E}, \mathrm{Mg}, \mathrm{Fe}$, vitamin $\mathrm{B}_{1}$, vitamin $\mathrm{A}$, Se, vitamin $\mathrm{C}$ and folic acid. The quintiles of adherence to a WDP showed the opposite tendency, the highest quintile was associated with the highest percentage of individuals with noncompliance of recommendations for iodine, vitamin $\mathrm{E}, \mathrm{Mg}$, $\mathrm{Fe}$, vitamin $\mathrm{A}, \mathrm{Se}$, vitamin $\mathrm{C}$ and folic acid.

Fig. 1 shows the average number of nutrients with unmet nutrient intakes across quintiles of dietary pattern score. The higher the quintile for the MDP, the lower the number of unmet nutrient intakes. The WDP showed the opposite tendency, with increasing quintiles. There was also an increase in the average of unmet nutrient intakes (Fig. 2).

Table 4 shows the OR for not achieving the daily recommended intakes using alternative cut-off points of six or ten unmet nutrient intakes according to quintiles of adherence to an MDP and to a WDP, adjusted for age and sex. The OR for not fulfilling the daily recommended intakes decreased according to the quintiles of adherence to MDP and the OR increased as the WDP score increased. The analysis adjusted for other variables, such as marital status, employment and smoking did not modify the results.

\section{Discussion}

We identified two dietary patterns in this population group, the Mediterranean and the Western. Individuals with a higher score for the MDP ate more fruits and vegetables, fish, poultry and legumes, low-fat dairy, and olive oil and had a healthier lifestyle. They also had a better nutrient profile, with a lower prevalence of individuals showing inadequate intakes of micronutrients. The WDP was associated to a higher intake of red and processed meats, eggs, sauces, pre-cooked food, fast food, energy soft drinks, sweets, whole dairy products and potatoes.

Fat intake was not associated with quintiles of adherence to the MDP. In fact, the proportion of energy coming from MUFA and PUFA was similar across quintiles of adherence to both dietary patterns (about $15-16 \%$ and 5-6\%, respectively). However, the MUFA/SFA ratio increased across 


\section{WS British Journal of Nutrition}

Table 2. Characteristics of the 17197 participants of the Seguimiento Universidad de Navarra cohort according to quintiles of adherence to the Mediterranean (MDP) and Western (WDP) dietary patterns (Mean values and standard deviations)

\begin{tabular}{|c|c|c|c|c|c|c|c|c|c|c|c|c|c|c|c|c|c|c|c|c|}
\hline & \multicolumn{10}{|c|}{ MDP } & \multicolumn{10}{|c|}{ WDP } \\
\hline & \multirow{2}{*}{\multicolumn{2}{|c|}{$\begin{array}{l}\text { Q1 }(n \text { 3439) } \\
\leq-0.84\end{array}$}} & \multirow{2}{*}{\multicolumn{2}{|c|}{$\begin{array}{c}\text { Q2 }(n 3440) \\
-0.85 \text { to } \\
-0.34\end{array}$}} & \multirow{2}{*}{\multicolumn{2}{|c|}{$\begin{array}{c}\text { Q3 }(n \text { 3439) } \\
-0.35 \text { to } 0.14\end{array}$}} & \multirow{2}{*}{\multicolumn{2}{|c|}{$\begin{array}{c}\text { Q4 }(n 3440) \\
0.15-0.76\end{array}$}} & \multirow{2}{*}{\multicolumn{2}{|c|}{$\begin{array}{l}\text { Q5 }(n \text { 3439) } \\
\quad \geq 0.77\end{array}$}} & \multirow{2}{*}{\multicolumn{2}{|c|}{$\begin{array}{l}\text { Q1 }(n \text { 3439) } \\
\leq-0.81\end{array}$}} & \multirow{2}{*}{\multicolumn{2}{|c|}{$\begin{array}{l}\text { Q2 }(n 3440) \\
-0.82 \text { to }\end{array}$}} & \multirow{2}{*}{\multicolumn{2}{|c|}{$\begin{array}{l}\text { Q3 }(n 3439) \\
-0.33 \text { to } 0.13\end{array}$}} & \multirow{2}{*}{\multicolumn{2}{|c|}{$\begin{array}{c}\text { Q4 }(n 3440) \\
0.14-0.74\end{array}$}} & \multirow{2}{*}{\multicolumn{2}{|c|}{$\begin{array}{l}\text { Q5 }(n \text { 3439) } \\
\quad \geq 0.75\end{array}$}} \\
\hline & & & & & & & & & & & & & & & & & & & & \\
\hline & Mean & SD & Mean & SD & Mean & SD & Mean & SD & Mean & SD & Mean & SD & Mean & SD & Mean & SD & Mean & SD & Mean & SD \\
\hline Women (\%) & \multicolumn{2}{|c|}{$49 \cdot 8$} & \multicolumn{2}{|c|}{54.8} & \multicolumn{2}{|c|}{60.5} & \multicolumn{2}{|c|}{$64 \cdot 3$} & \multicolumn{2}{|c|}{68.9} & \multicolumn{2}{|c|}{68.5} & \multicolumn{2}{|c|}{$66 \cdot 0$} & 61 & & & & & \\
\hline Age (years) & $37 \cdot 0$ & 11.4 & 38.1 & $12 \cdot 2$ & 38.5 & $12 \cdot 0$ & 39.5 & $12 \cdot 5$ & $40 \cdot 2$ & $12 \cdot 9$ & $42 \cdot 7$ & $13 \cdot 0$ & $40 \cdot 8$ & $12 \cdot 4$ & 38.5 & $12 \cdot 0$ & 36.8 & 11.4 & 34.6 & $10 \cdot 8$ \\
\hline Smoking (\%) & & & & & & & & & & & & & & & & & & & & \\
\hline Current smoker & 24 & & 23 & & & & & & & & & & & & 21 & & & & & \\
\hline Ex-smoker & 26 & & & & & & & & & & & & 3 & & 30 & & & & & \\
\hline $\begin{array}{l}\text { Sedentary activities } \\
(\mathrm{h} / \mathrm{d})\end{array}$ & 5.9 & $2 \cdot 1$ & 5.9 & $2 \cdot 1$ & $5 \cdot 7$ & $2 \cdot 1$ & $5 \cdot 7$ & $2 \cdot 2$ & 5.6 & $2 \cdot 2$ & 5.5 & $2 \cdot 1$ & $5 \cdot 7$ & $2 \cdot 1$ & $5 \cdot 8$ & $2 \cdot 1$ & $5 \cdot 9$ & $2 \cdot 1$ & $6 \cdot 0$ & $2 \cdot 2$ \\
\hline $\begin{array}{l}\text { Physical activity } \\
\text { (MET-h/week) }\end{array}$ & $21 \cdot 6$ & $20 \cdot 2$ & $22 \cdot 7$ & $19 \cdot 7$ & $24 \cdot 1$ & $20 \cdot 8$ & 24.9 & $22 \cdot 5$ & $27 \cdot 4$ & $25 \cdot 7$ & $26 \cdot 0$ & $23 \cdot 6$ & 23.6 & $21 \cdot 2$ & 23.3 & $20 \cdot 6$ & $23 \cdot 1$ & 20.7 & 24.7 & 23.5 \\
\hline Snacking (\%) & 34 & & & & & & & & & & & & & & 33 & & & & & \\
\hline $\begin{array}{l}\text { Fat intake (\% of } \\
\text { energy) }\end{array}$ & $37 \cdot 1$ & $6 \cdot 9$ & $36 \cdot 7$ & $6 \cdot 4$ & $36 \cdot 8$ & $6 \cdot 4$ & $36 \cdot 6$ & $6 \cdot 7$ & $35 \cdot 2$ & $6 \cdot 8$ & $32 \cdot 4$ & 7.6 & 35.6 & $6 \cdot 4$ & $36 \cdot 8$ & $5 \cdot 9$ & 38.0 & 5.5 & 39.5 & 5.4 \\
\hline MUFA ( $\%$ of energy) & $15 \cdot 4$ & 3.8 & $15 \cdot 6$ & 3.5 & $15 \cdot 9$ & 3.7 & $16 \cdot 0$ & 3.9 & $15 \cdot 4$ & 3.9 & $14 \cdot 5$ & 4.6 & $15 \cdot 5$ & 3.9 & $15 \cdot 8$ & 3.5 & $16 \cdot 1$ & 3.3 & $16 \cdot 5$ & $3 \cdot 1$ \\
\hline PUFA (\% of energy) & $5 \cdot 3$ & $1 \cdot 8$ & $5 \cdot 2$ & 1.6 & $5 \cdot 2$ & 1.5 & $5 \cdot 2$ & 1.5 & $5 \cdot 0$ & 1.4 & 4.5 & $1 \cdot 6$ & 4.9 & 1.4 & $5 \cdot 2$ & 1.5 & 5.5 & 1.5 & $5 \cdot 9$ & 1.5 \\
\hline SFA (\% of energy) & $13 \cdot 6$ & 3.6 & $12 \cdot 9$ & $3 \cdot 1$ & 12.5 & $3 \cdot 0$ & $12 \cdot 0$ & $3 \cdot 0$ & $11 \cdot 1$ & 3.0 & $10 \cdot 3$ & 3.4 & 11.9 & 3.0 & $12 \cdot 6$ & $2 \cdot 9$ & $12 \cdot 2$ & $2 \cdot 7$ & $14 \cdot 1$ & $2 \cdot 8$ \\
\hline MUFA/SFA ratio & $1 \cdot 18$ & 0.32 & 1.25 & 0.30 & $1 \cdot 30$ & 0.32 & 1.38 & 0.36 & 1.43 & 0.38 & 1.48 & 0.49 & 1.35 & 0.34 & $1 \cdot 29$ & 0.30 & 1.25 & 0.26 & $1 \cdot 19$ & 0.22 \\
\hline $\begin{array}{l}\text { Carbohydrate intake } \\
\text { (\% of energy) }\end{array}$ & $43 \cdot 8$ & 8.0 & $43 \cdot 4$ & $7 \cdot 2$ & $43 \cdot 1$ & $7 \cdot 2$ & $42 \cdot 8$ & $7 \cdot 4$ & $43 \cdot 6$ & $7 \cdot 8$ & $46 \cdot 9$ & 8.7 & 43.7 & 7.5 & 43.0 & $6 \cdot 9$ & $42 \cdot 2$ & $6 \cdot 4$ & $40 \cdot 9$ & $6 \cdot 4$ \\
\hline $\begin{array}{l}\text { Protein intake } \\
\text { (\% of energy) }\end{array}$ & $16 \cdot 7$ & 3.5 & $17 \cdot 7$ & $2 \cdot 9$ & $18 \cdot 1$ & 3.0 & $18 \cdot 6$ & 3.1 & $19 \cdot 7$ & 3.5 & 18.5 & $4 \cdot 3$ & $18 \cdot 6$ & 3.3 & $18 \cdot 1$ & $3 \cdot 1$ & $17 \cdot 9$ & $2 \cdot 8$ & $17 \cdot 7$ & $2 \cdot 9$ \\
\hline $\begin{array}{l}\text { Alcohol intake } \\
\text { (\% of energy) }\end{array}$ & 2.4 & 3.8 & $2 \cdot 3$ & 3.2 & $2 \cdot 0$ & 3.0 & $2 \cdot 0$ & $2 \cdot 9$ & 1.6 & $2 \cdot 4$ & $2 \cdot 2$ & 3.6 & $2 \cdot 2$ & 3.3 & $2 \cdot 2$ & $3 \cdot 1$ & 1.9 & $2 \cdot 7$ & 1.9 & $2 \cdot 7$ \\
\hline $\begin{array}{l}\text { Fibre intake }(\mathrm{g} / \mathrm{d}) \\
\text { Micronutrients }\end{array}$ & $20 \cdot 8$ & 6.5 & $24 \cdot 0$ & 7.4 & $26 \cdot 0$ & $7 \cdot 8$ & $29 \cdot 1$ & $9 \cdot 2$ & 36.9 & $13 \cdot 4$ & 34.0 & $12 \cdot 3$ & 29.4 & $9 \cdot 6$ & $27 \cdot 0$ & $9 \cdot 1$ & 24.9 & $8 \cdot 8$ & 21.5 & 8.9 \\
\hline $\mathrm{Zn}(\mathrm{mg} / \mathrm{d})$ & 13 & 6 & 15 & 8 & 17 & 9 & 19 & 11 & 24 & 16 & 22 & 15 & 19 & 12 & 17 & 9 & 16 & 8 & 15 & 7 \\
\hline lodine $(\mu \mathrm{g} / \mathrm{d})$ & 305 & 178 & 312 & 168 & 324 & 186 & 343 & 198 & 397 & 244 & 393 & 228 & 350 & 187 & 330 & 186 & 319 & 182 & 288 & 194 \\
\hline Vitamin E (mg/d) & $6 \cdot 7$ & $2 \cdot 7$ & $6 \cdot 9$ & $3 \cdot 1$ & $7 \cdot 0$ & $3 \cdot 1$ & $7 \cdot 2$ & $3 \cdot 2$ & $7 \cdot 2$ & 3.4 & $7 \cdot 3$ & $3 \cdot 2$ & $7 \cdot 1$ & $2 \cdot 9$ & $7 \cdot 0$ & $3 \cdot 1$ & $6 \cdot 9$ & $3 \cdot 1$ & $6 \cdot 6$ & $3 \cdot 3$ \\
\hline Vitamin $D(\mu \mathrm{g} / \mathrm{d})$ & $2 \cdot 8$ & 1.4 & $3 \cdot 1$ & 1.7 & 3.5 & $2 \cdot 1$ & 3.9 & $2 \cdot 3$ & 4.9 & 3.4 & 3.9 & $2 \cdot 5$ & 3.8 & $2 \cdot 4$ & 3.6 & $2 \cdot 2$ & 3.5 & $2 \cdot 4$ & 3.4 & $2 \cdot 4$ \\
\hline$P(\mathrm{mg} / \mathrm{d})$ & 1702 & 296 & 1811 & 300 & 1880 & 323 & 1985 & 355 & 2220 & 460 & 2021 & 439 & 1955 & 390 & 1901 & 367 & 1873 & 361 & 1847 & 381 \\
\hline $\mathrm{Na}(\mathrm{mg} / \mathrm{d})$ & 4178 & 2023 & 4064 & 2061 & 3958 & 1939 & 3906 & 2528 & 3616 & 1926 & 3398 & 1101 & 3600 & 1258 & 3783 & 1642 & 4027 & 1943 & 4915 & 3424 \\
\hline$M g(m g / d)$ & 352 & 53 & 382 & 58 & 401 & 62 & 428 & 69 & 497 & 98 & 462 & 95 & 427 & 77 & 408 & 76 & 394 & 72 & 368 & 75 \\
\hline $\mathrm{K}(\mathrm{mg} / \mathrm{d})$ & 3749 & 732 & 4219 & 755 & 4529 & 830 & 4984 & 931 & 6132 & 1501 & 5358 & 1503 & 4898 & 1157 & 4660 & 1182 & 4501 & 1103 & 4194 & 1109 \\
\hline $\mathrm{Fe}(\mathrm{mg} / \mathrm{d})$ & $14 \cdot 4$ & $2 \cdot 2$ & $15 \cdot 8$ & $2 \cdot 3$ & $16 \cdot 5$ & 2.5 & $17 \cdot 6$ & $2 \cdot 8$ & $20 \cdot 3$ & $4 \cdot 3$ & $18 \cdot 1$ & $4 \cdot 1$ & $17 \cdot 3$ & 3.3 & $16 \cdot 9$ & $3 \cdot 3$ & $16 \cdot 5$ & 3.3 & 15.9 & 3.4 \\
\hline $\mathrm{Ca}(\mathrm{mg} / \mathrm{d})$ & 1102 & 350 & 1148 & 357 & 1194 & 383 & 1251 & 403 & 1409 & 497 & 1388 & 454 & 1276 & 402 & 1214 & 383 & 1161 & 374 & 1065 & 387 \\
\hline Vitamin $B_{12}(\mu \mathrm{g} / \mathrm{d})$ & $7 \cdot 8$ & 3.4 & $8 \cdot 6$ & 3.9 & $9 \cdot 2$ & $4 \cdot 0$ & $10 \cdot 0$ & $4 \cdot 6$ & $11 \cdot 7$ & $6 \cdot 2$ & 8.9 & $4 \cdot 2$ & $9 \cdot 5$ & $4 \cdot 3$ & $9 \cdot 4$ & 4.5 & $9 \cdot 6$ & 4.9 & $10 \cdot 0$ & $5 \cdot 6$ \\
\hline Vitamin $B_{6}(\mathrm{mg} / \mathrm{d})$ & $2 \cdot 1$ & 0.5 & $2 \cdot 4$ & 0.5 & $2 \cdot 6$ & 0.5 & $2 \cdot 9$ & 0.6 & $3 \cdot 6$ & 0.9 & 3.0 & 0.9 & $2 \cdot 8$ & 0.8 & $2 \cdot 7$ & 0.7 & $2 \cdot 6$ & 0.7 & $2 \cdot 4$ & 0.7 \\
\hline Vitamin $B_{3}(m g / d)$ & 36 & 6 & 39 & 6 & 41 & 6 & 43 & 6 & 49 & 10 & 41 & 8 & 42 & 8 & 42 & 8 & 42 & 9 & 43 & 10 \\
\hline Vitamin $B_{2}(\mathrm{mg} / \mathrm{d})$ & $2 \cdot 0$ & 0.4 & $2 \cdot 1$ & 0.4 & $2 \cdot 2$ & 0.5 & $2 \cdot 3$ & 0.5 & $2 \cdot 6$ & 0.7 & $2 \cdot 4$ & 0.6 & $2 \cdot 3$ & 0.5 & $2 \cdot 2$ & 0.5 & $2 \cdot 1$ & 0.5 & $2 \cdot 1$ & 0.5 \\
\hline Vitamin $B_{1}(\mathrm{mg} / \mathrm{d})$ & 1.5 & 0.3 & 1.7 & 0.3 & $1 \cdot 8$ & 0.3 & 1.9 & 0.3 & $2 \cdot 2$ & 0.4 & 1.9 & 0.4 & 1.9 & 0.4 & $1 \cdot 8$ & 0.4 & $1 \cdot 8$ & 0.4 & $1 \cdot 7$ & 0.4 \\
\hline Vitamin $A(\mu \mathrm{g} / \mathrm{d})$ & 1187 & 732 & 1498 & 913 & 1733 & 991 & 2144 & 1285 & 3029 & 2078 & 2447 & 1796 & 2112 & 1394 & 1910 & 1316 & 1737 & 1227 & 1385 & 1145 \\
\hline $\operatorname{Se}(\mu \mathrm{g} / \mathrm{d})$ & 86 & 25 & 93 & 25 & 96 & 27 & 99 & 28 & 107 & 35 & 95 & 28 & 98 & 26 & 97 & 27 & 96 & 28 & 94 & 37 \\
\hline Vitamin C (mg/d) & 180 & 90 & 225 & 101 & 257 & 113 & 305 & 130 & 411 & 204 & 354 & 189 & 300 & 146 & 273 & 140 & 246 & 128 & 204 & 123 \\
\hline Folic acid $(\mu \mathrm{g} / \mathrm{d})$ & 227 & 81 & 293 & 90 & 336 & 102 & 402 & 118 & 532 & 205 & 385 & 200 & 351 & 152 & 336 & 154 & 333 & 140 & 321 & 139 \\
\hline
\end{tabular}

Q, quintile; MET, metabolic equivalent. 
Table 3. Percentages (\%) of participants who did not comply with recommended nutrient intakes according to quintiles of adherence to the Mediterranean (MDP) and Western (WDP) dietary patterns calculated through the probabilistic approach

\begin{tabular}{|c|c|c|c|c|c|c|c|c|c|c|c|c|c|c|c|}
\hline Micronutrients & $\mathrm{Zn}$ & lodine & Vit. E & $\mathrm{P}$ & $\mathrm{Mg}$ & $\mathrm{Fe}$ & Vit. $B_{12}$ & Vit. $B_{6}$ & Vit. $B_{3}$ & Vit. $B_{2}$ & Vit. $B_{1}$ & Vit. A & $\mathrm{Se}$ & Vit. C & Folic acid \\
\hline \multicolumn{16}{|l|}{ MDP } \\
\hline Q1 & 8 & 9 & 94 & 0 & 21 & 20 & 1 & 2 & 0 & 1 & 2 & 23 & 4 & 8 & 19 \\
\hline Q2 & 4 & 8 & 93 & 0 & 12 & 13 & 1 & 0 & 0 & 1 & 1 & 15 & 2 & 4 & 16 \\
\hline Q3 & 3 & 9 & 92 & 0 & 8 & 12 & 1 & 0 & 0 & 1 & 1 & 11 & 2 & 3 & 15 \\
\hline Q4 & 2 & 7 & 90 & 0 & 5 & 8 & 1 & 0 & 0 & 0 & 0 & 7 & 1 & 2 & 12 \\
\hline Q5 & 1 & 7 & 89 & 0 & 2 & 3 & 1 & 0 & 0 & 0 & 0 & 4 & 2 & 1 & 10 \\
\hline \multicolumn{16}{|l|}{ WDP } \\
\hline Q1 & 3 & 4 & 91 & 0 & 3 & 8 & 1 & 0 & 0 & 0 & 0 & 4 & 2 & 1 & 13 \\
\hline Q2 & 2 & 6 & 92 & 0 & 5 & 11 & 0 & 0 & 0 & 0 & 0 & 6 & 1 & 1 & 11 \\
\hline Q3 & 3 & 8 & 92 & 0 & 8 & 12 & 1 & 0 & 0 & 1 & 1 & 10 & 2 & 2 & 13 \\
\hline Q4 & 4 & 9 & 92 & 0 & 11 & 14 & 1 & 1 & 0 & 1 & 1 & 13 & 2 & 4 & 16 \\
\hline Q5 & 5 & 14 & 92 & 0 & 21 & 13 & 1 & 1 & 0 & 1 & 2 & 27 & 4 & 10 & 20 \\
\hline
\end{tabular}

Vit., vitamin; Q, quintile.

quintiles of the MDP but decreased across quintiles of the WDP. In Spain and other Mediterranean countries, the nutrient recommendations for fat intake include a level of consumption as high as $35 \%$ of total energy intake ${ }^{(24)}$ due to the elevated consumption of olive oil in the population. Such consumption implies a high intake of MUFA in individuals, even among those not adhering to the nutrient recommendations ${ }^{(25)}$. It is worth noting that the SUN sample includes only individuals with high levels of education, which is associated with better diet profiles ${ }^{(26-29)}$. The lack of variation in educational levels represents the strength of the study precluding confounding due to educational status, i.e. restriction was used. Restriction is an excellent technique for preventing or at least reducing confounding by known factors, and it is recommended by methodologists because restriction is usually more effective than multivariable adjustment to control for potential confounding ${ }^{(30)}$. However, restriction represents also a limitation of the present findings with respect to their generalisability.

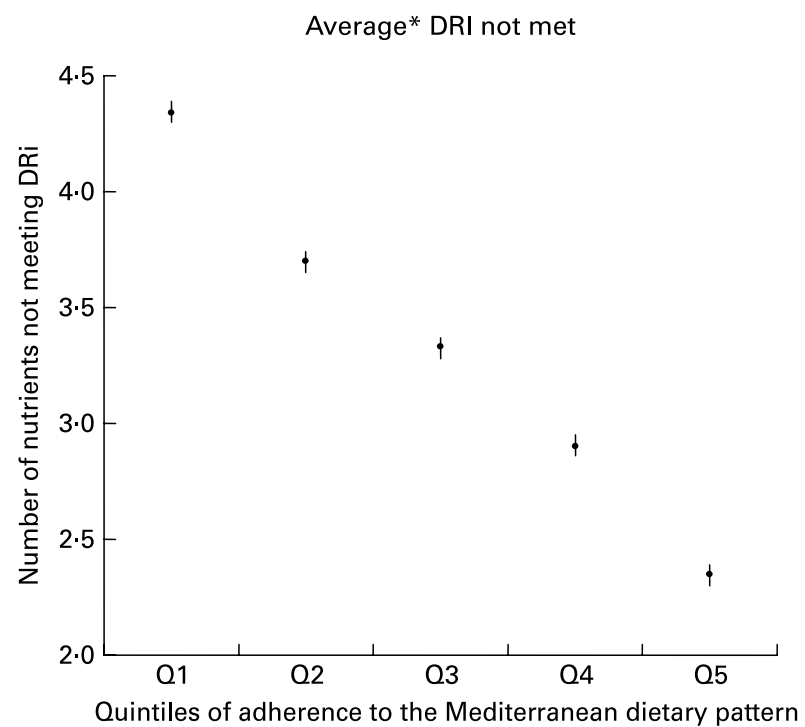

Fig. 1. Average number of nutrients with intakes not meeting the recommended levels across quintiles of diet pattern score. DRI, dietary reference intake; $Q$, quintile. *Adjusted for age and sex.
Studies conducted in non-Mediterranean countries have identified several dietary patterns, the Prudent and Western patterns ${ }^{(31-34)}$, the Healthy, Western, Drinker and Sweets patterns ${ }^{(35,36)}$, the Health energy density, Traditional and Health-conscious patterns ${ }^{(37)}$ and the Healthy, Western and Traditional patterns ${ }^{(38)}$. The healthiest of these (namely, the Prudent, Healthy or Health-conscious patterns) have similarities with the Mediterranean pattern defined in the present study and others conducted in the Mediterranean ${ }^{(39)}$ : a positive correlation with intakes of fruits; green leafy vegetables; poultry and fish; certain lifestyle habits such as non-smoking and being more physically active. However, differences have consistently arisen when analysing the association of the dietary patterns with their nutrient intake profiles, especially in relation to fat intake. Wu et al. ${ }^{(40)}$ defined a Prudent and a Western pattern in the cohort of men of the Health Professionals Follow-up Study and found that a higher quintile of the Prudent pattern score was correlated with higher intakes of protein and PUFA, and lower intakes of SFA. No information was given for the values of MUFA intake. Moreover, Zhang et al. ${ }^{(32)}$ identified a Prudent and

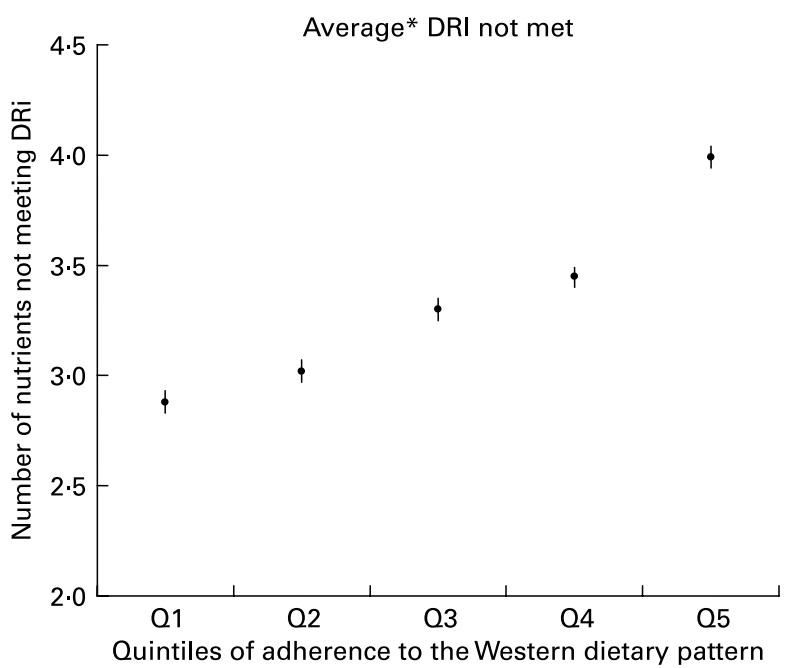

Fig. 2. Average number of nutrients with intakes not meeting the recommended levels across quintiles of diet pattern score. DRI, dietary reference intake; $Q$, quintile. *Adjusted for age and sex. 
a Western pattern in a sample of female nurses in the US, and showed characteristics of nutrient intake across quintiles of dietary pattern scores. A higher quintile for a Prudent pattern score was associated to a higher intake of carbohydrates, protein, total fibre, $\mathrm{Mg}$ and total Fe. The percentage of energy from total fat and SFA decreased with the increasing quintiles, but the intake of MUFA also decreased. PUFA intake showed a slight increase. A higher quintile of adherence to the Prudent pattern was associated to a higher percentage of energy coming from carbohydrates (up to $53 \%$ in the fifth quintile). In addition, Fung et al. ${ }^{(33)}$ in the Nurses' Health Study identified and categorised individuals into quintiles of adherence to a Prudent diet score. Individuals in the fifth quintile of this pattern showed higher intakes of protein, carbohydrate, fibre, cholesterol and also PUFA. Their intakes of MUFA, SFA and trans-fatty acids were lower than individuals in the first quintile. In the sample of the Baltimore Longitudinal Study of Aging, Newby et al. ${ }^{(35)}$ defined six food patterns using factor analysis. The distribution of the sample according to quintiles of factor 1 , the 'Healthy' profile, showed that a higher quintile of the score was associated to a higher percentage of energy coming from carbohydrates and proteins, and a lower percentage coming from fat and saturated fat. In a study conducted in a sample of female teachers in Iran $^{(38)}$, three dietary patterns were identified: the Healthy; Western; Traditional patterns. A higher quintile of adherence to the Healthy pattern score was related to a higher percentage of energy coming from proteins and carbohydrates and a lower percentage of energy coming from fat. No information was given about the fat intake profile. In the SUN sample presented here, the MUFA/SFA ratio was directly associated with the MDP and inversely associated with the WDP, showing a healthier profile of the quality of fat intake when comparing with the other studies conducted in non-Mediterranean countries.

Diet pattern analysis has been used to predict disease as demonstrated in certain studies where Body Mass Index (BMI), type 2 diabetes, CVD, certain cancers, metabolic syndrome and mortality have been correlated with specific dietary patterns $^{(1)}$. Within the context of the EUropean micronutrient RECommendations Aligned framework, a review on studies evaluating the validity of diet patterns a priori or a posteriori defined to assess nutrient intake adequacy has been conducted, showing reasonable correlations ${ }^{(9)}$. The study presented here, although it is not a proper validation study, shows that as adherence to the Mediterranean diet increases, the probability of not fulfilling the nutrient recommendations decreases.

\section{Acknowledgements}

We are indebted to the participants of the SUN Project for their continued cooperation and participation. We thank other members of the SUN Group: J. de Irala; C. de la Fuente; J. A. Martínez; M. Seguí-Gómez; A. Alonso; J. J. Beunza; M. Serrano-Martínez; F. Guillén-Grima; Z. Vazquez; S. Benito; J. Doreste; P. Henriquez. Funding/ support. The Spanish Government (Instituto de Salud Carlos III, Fondo de Investigaciones Sanitarias, projects PI042241, PI040233, PI050976, PI070240, PI0801943 and RD 06/ 
0045) and the Navarra Regional Government (PI41/2005, PI36/ 2008) have supported the SUN study. The study reported herein has been carried out within the EUropean micronutrient RECommendations Aligned network of excellence (www. eurreca.org), financially supported by the Commission of the European Communities, specific Research, Technology and Development Programme Quality of Life and Management of Living Resources, within the Sixth Framework Programme, contract no. 036196. The present report does not necessarily reflect the Commission's views or its future policy in this area. Authors' contributions. L. S.-M. carried out the design and drafted the manuscript. M. B.-R. participated in the conception and design and was responsible for the statistical analysis. B. R. V. participated in the bibliographic search, article screening and helped in the draft of the manuscript. K. P. screened the literature and participated in the discussion of the paper. A. S.-V. commented on drafts of the paper. M. A. M.-G. provided expert advice on data interpretation and discussion of the paper. All authors participated in the critical revision of the manuscript and approved the final version. The authors have no conflict of interests to report.

\section{References}

1. Kant AK (2004) Dietary patterns and health outcomes. J Am Diet Assoc 104, 615-635.

2. Moeller SM, Reedy J, Millen AE, et al. (2007) Dietary patterns: challenges and opportunities in dietary patterns research an Experimental Biology workshop, April 1, 2006. J Am Diet Assoc 107, 1233-1239.

3. Newby PK \& Tucker KL (2004) Empirically derived eating patterns using factor or cluster analysis: a review. Nutr Rev 62, $177-203$.

4. Hu FB (2002) Dietary pattern analysis: a new direction in nutritional epidemiology. Curr Opin Lipidol 13, 3-9.

5. van Dam RM (2005) New approaches to the study of dietary patterns. Br J Nutr 93, 573-574.

6. Peppa M, Goldberg T, Cai W, et al. (2002) Glycotoxins: a missing link in the 'relationship of dietary fat and meat intake in relation to risk of type 2 diabetes in men'. Diabetes Care 25, $1898-1899$.

7. Bach A, Serra-Majem L, Carrasco JL, et al. (2006) The use of indexes evaluating the adherence to the Mediterranean diet in epidemiological studies: a review. Public Health Nutr 9, $132-146$.

8. Willett WC \& McCullough ML (2008) Dietary pattern analysis for the evaluation of dietary guidelines. Asia Pac J Clin Nutr 17, Suppl. 1, 75-78.

9. Román-Viñas B, Ribas-Barba L, Ngo J, et al. (2009) Validity and reproducibility of dietary patterns to assess nutrient intake adequacy. Br J Nutr 101, Suppl. 2, S21-S28.

10. Seguí-Gómez M, de la Fuente C, Vázquez Z, et al. (2006) Cohort profile: the 'Seguimiento Universidad de Navarra' (SUN) study. Int J Epidemiol 35, 1417-1422, Epublication 22 October 2006.

11. Martin-Moreno JM, Boyle P, Gorgojo L, et al. (1993) Development and validation of a food frequency questionnaire in Spain. Int $J$ Epidemiol 22, 512-519.

12. Moreiras O, Carvajal A \& Cabrera L (2005) Tablas de composición de alimentos (Food Composition Tables), 9th ed. Madrid: Pirámide.

13. Mataix Verdú J \& Mañas Almendros M (2003) Tabla de composición de alimentos españoles (Food Composition Table Spanish), 4th ed. Granada: Ed. Universidad de Granada.
14. Pett MA, Lackey NR \& Sullivan JJ (2003) Making Sense of Factor Analysis: The Use of Factor Analysis for Instrument Development in Health Care Research. Thousand Oaks, CA: Sage Publications.

15. National Academy Press (2002) Dietary Reference Intakes for Thiamin, Riboflavin, Niacin, Vitamin $B_{6}$, Folate, Vitamin $B_{12}$, Pantothenic Acid, Biotin, and Choline. 1st ed. Washington, DC: National Academy Press, pp. 58-122, 150-195, 306-356. Available at http://www.nap.edu/books/0309065542/ html/1.html (accessed March 2009).

16. National Academy Press (2000) Dietary Reference Intakes for Vitamin C, Vitamin E, Selenium, and Carotenoids, 1st ed. Washington, DC: National Academy Press, pp. 95-185, 284-324. Available at http://www.nap.edu/books/0309069351/ html/95.html (accessed March 2009).

17. Institute of Medicine Food and Nutrition Board (1997) Dietary Reference Intakes for Calcium, Phosphorus, Magnesium, Vitamin $D$, and Fluoride. Washington, DC: National Academy Press.

18. Institute of Medicine Food and Nutrition Board (2001) Dietary Reference Intakes for Vitamin A, Vitamin K, Arsenic, Boron, Chromium, Copper, Iodine, Iron, Manganese, Molybdenum, Nickel, Silicon, Vanadium, and Zinc. Washington, DC: National Academy Press.

19. World Health Organization, Food and Agriculture Organization of the United Nations (2004) Vitamin and Mineral Requirements in Human Nutrition, 2nd ed. Geneva: World Health Organization and Rome, Food and Agriculture Organization of the United Nations. Available at http://whqlibdoc.who.int/ publications/2004/9241546123.pdf (accessed March 2009).

20. Ministerios del Interior, de Sanidad y Consumo y de Educación y Cultura (2000) Nutrición saludable y prevención de los trastornos alimentarios. Available at http://www. mepsyd.es/cide/espanol/publicaciones/materiales/salud/inn1999ns/ inn1999ns1.pdf (accessed March 2009).

21. Institute of Medicine, Food and Nutrition Board (2000) Dietary Reference Intakes: Applications in Dietary Assessment. Washington, DC: National Academy Press.

22. Martínez-González MA, López-Fontana C, Varo JJ, et al. (2005) Validation of the Spanish version of the physical activity questionnaire used in the Nurses' Health Study and the Health Professionals' Follow-up Study. Public Health Nutr 8, 920-927.

23. Ainsworth BE, Haskell WL, Whitt MC, et al. (2000) Compendium of physical activities: an update of activity codes and MET intensities. Med Sci Sports Exerc 32, Suppl. 9, S498-S504.

24. Serra-Majem L \& Aranceta J, on behalf of the SENC Working Group on Nutritional Objectives for the Spanish Population, Spanish Society of Community Nutrition (2001) Nutritional objectives for the Spanish population. Consensus from the Spanish society of community nutrition. Public Health Nutr 4, 1409-1413.

25. Serra-Majem L, Ribas-Barba L, Salvador G, et al. (2007) Trends in energy and nutrient intake and risk of inadequate intakes in Catalonia, Spain (1992-2003). Public Health Nutr 10, 1354-1367.

26. Schulze MB, Hoffmann K, Kroke A, et al. (2001) Dietary patterns and their association with food and nutrient intake in the European Prospective Investigation into Cancer and Nutrition (EPIC) - Potsdam study. Br J Nutr 85, 363-373. Erratum in: Br J Nutr 2002, 87, 279.

27. Tseng M \& DeVellis RF (2001) Fundamental dietary patterns and their correlates among US whites. J Am Diet Assoc 101, 929-932.

28. Sanchez-Villegas A, Delgado-Rodriguez M, Martínez-González MA, et al. (2003) Gender, age, socio-demographic and lifestyle factors associated with major dietary patterns in the Spanish project SUN (Seguimiento Universidad de Navarra). Eur $J$ Clin Nutr 57, 285-292. 
29. Yang EJ, Kerver JM \& Song WO (2005) Dietary patterns of Korean Americans described by factor analysis. J Am Coll Nutr 24, 115-121.

30. Rothman KJ, Greenland S \& Lash TL (2008) Modern Epidemiology, 3rd ed. Philadelphia, PA: Lippincott Williams.

31. Hu FB, Rimm E, Smith-Warner SA, et al. (1999) Reproducibility and validity of dietary patterns assessed with a food-frequency questionnaire. Am J Clin Nutr 69, 243-249.

32. Zhang C, Schulze MB, Solomon CG, et al. (2007) A prospective study of dietary patterns, meat intake and the risk of gestational diabetes mellitus. Diabetologia 49, 2604-2613.

33. Fung TT, Willett WC, Stampfer MJ, et al. (2001) Dietary patterns and the risk of coronary heart disease in women. Arch Intern Med 161, 1857-1862.

34. Heidemann C, Schulze MB, Franco OH, et al. (2008) Dietary patterns and risk of mortality from cardiovascular disease, cancer, and all causes in a prospective cohort of women. Circulation 118, 230-237, Epublication 23 June 2008.
35. Newby PK, Weismayer C, Akesson A, et al. (2006) Long-term stability of food patterns identified by use of factor analysis among Swedish women. J Nutr 136, 626-633.

36. Khani BR, Ye W, Terry P, et al. (2004) Reproducibility and validity of major dietary patterns among Swedish women assessed with a food-frequency questionnaire. J Nutr 134, 1541-1545.

37. Beaudry M, Galibois I \& Chaumette P (1998) Dietary patterns of adults in Québec and their nutritional adequacy. Can $J$ Public Health 89, 347-351.

38. Esmaillzadeh A, Kimiagar M, Mehrabi Y, et al. (2007) Dietary patterns and markers of systemic inflammation among Iranian women. J Nutr 137, 992-998.

39. Costacou T, Bamia C, Ferrari P, et al. (2003) Tracing the Mediterranean diet through principal components and cluster analyses in the Greek population. Eur J Clin Nutr 57, 1378-1385.

40. Wu K, Hu FB, Willett WC, et al. (2006) Dietary patterns and risk of prostate cancer in U.S. men. Cancer Epidemiol Biomarkers Prev 15, 167-171. 